\title{
Genotoxic Potentials of Natural Products Detected by a Short-Term Test Using Diploid Strains of Aspergillus nidulans
}

\author{
M.J. Salvador ${ }^{1,2}$, T.D. Zucchi ${ }^{3}$, E.C. Schinor ${ }^{2}$, D.A. Dias ${ }^{2}$, O.L.A.D. Zucchi ${ }^{2}$, P. Poli ${ }^{4}$ and \\ T.M.A.D. Zucchi ${ }^{*}, 3,5$
}

${ }^{I}$ Curso de Farmácia, Departamento de Fisiologia Vegetal, Instituto de Biologia, Universidade Estadual de Campinas, Campinas, SP, Brasil; ${ }^{2}$ Departamento de Física e Química, Faculdade de Ciências Farmacêuticas de Ribeirão Preto, Universidade de São Paulo, Ribeirão Preto, SP, Brasil,; ${ }^{3}$ Centro de Pesquisas Biotecnológicas, Universidade de São Paulo, São Paulo, SP, Brasil; ${ }^{4}$ Departamento di Genética Antropológia Evoluzione, Universita di Parma, Parma, Itália; ${ }^{5}$ Departamento de Ciências Biológicas \& Biotecnologia, Universidade Estadual Paulista Júlio de Mesquita Filho (UNESP), Assis, SP, Brasil

\begin{abstract}
Main aim is to evaluate the genotoxic potentials of three classes of natural products, a sesquiterpene lactone (cynaropicrin), a saponin (stigmast-7en-3 $\beta$-ol-glucopyranoside) and a steroid (stigmasterol), at low doses, using the Homozygotization Index test (HI). This short-term test, deals with the determination of alterations in mitotic crossing-over frequencies eventually involving heterozygous auxotrophic genes in diploid strains of Aspergillus nidulans. In this way, treatments of UT448//UT184 and Dp II-I//UT184 diploid strains with the natural products showed that saponin and lactone significantly increased the homozygotization index (HI) of both strains, especially for the diploid Dp II-I//UT184. No effect was observed with the steroid. On this account it presents remarkable potentials to detect the genotoxic/carcinogenic effects of bioactive natural products. Furthermore, this is the first time the low doses effects of bioactive natural products were detected using $A$. nidulans.
\end{abstract}

Keywords: Natural products, Sesquiterpene lactone (cynaropicrin), Saponin (stigmast-7en-3 $\beta$-ol-glucopyranoside), Steroid (stigmasterol), Genotoxic potential, Mitotic crossing-over, Aspergillus nidulans short-term test.

\section{INTRODUCTION}

Even in the lack of adequate scientific basis, natural products have long been used in human therapeutics. Increased use of plant extracts by the pharmaceutical industry and the appearance of so-called nutraceutic foods indicate the need for systematic studies on medicinal plants mainly to evidence eventual hazardous effects, and to disclose efficient methods involved into such aimed at detection.

Plants provide an extraordinary reservoir of new molecules. Chemical compounds commonly isolated from plant species include steroids, terpenes, flavonoids, lactones, saponins, alkaloids, etc. These compounds are biosynthesized by the plant as a primary defense against their potential enemies, as bacteria, fungi, insects and other predator animals. Consequently they show a variety of biological effects, as anti-inflammatory [1], trypanocidal [2], antibacterial [3, 4], and anti-arteriosclerotic properties [5]. In addition, either direct, or indirectly they often integrate the composition of human daily food stuffs $[5,6]$. Therefore, studies to evidence chemical, toxicological and pharmacological properties of plant products (extracts, fractions and pure substances) are under urgent needs and should be strongly encouraged.

Evidently, before using a given product a crucial aspect

*Address correspondence to this author at Departamento de Departamento de Ciências Biológicas \& Biotecnologia, Universidade Estadual Paulista Júlio de Mesquita Filho (UNESP), Av. Don Antonio, 2100., CEP 19806900, Assis, SP, Brasil; E-mail: tzucchi@uol.com.br should rely on its safe use. For such, determination of genotoxic potentials and allied genotoxicity interval [7] under submutagenic doses is fundamental for searching new safe drugs and medicines originating from plant products. In addition, mitotic recombination is a process participating in numerous important biological events, such as DNA repair mechanisms [8], human genetic diseases, and cancer risks [9, $10]$. It also plays a role in the rearrangements occurring during immunoglobulin synthesis and it possibly also responds for the integration of the exogenous genetic material during cell transformation processes [9].

Physical and chemical agents can enhance DNA damage and induce mitotic crossing-over. Lesions caused by these agents can induce mitotic recombination that, on its turn, can indicate DNA damage [11]. On account of its wellunderstood classical genetics background the filamentous fungus Aspergillus nidulans is the ideal organism to provide information on mitotic recombination and related aspects. Because occurrence of diploid cells, mitotic recombination and haploidization take place during fungal parasexual and sexual cycles [12], produced haploid cells express the mitotic rearrangements occurring during the diploid phase. So, they can be used to determine the genotoxicity of a substance. On such grounds, Pires and Zucchi [13], developed a short-term test (Homozygotization Index, HI) that uses two A. nidulans diploid strains: UT184//UT448, with normal DNA repair mechanisms; and Dp II-I//UT184, presenting recombinational repair mechanisms, only. Both diploids bear several genetic markers scattered all over the eight fungal chromosomes, and the strain $D p$ II-I presents high sensibility 
for any kind of DNA damage, as reflected by increased recombination frequencies. Furthermore, Zucchi et al. [14] showed that mentioned short-term test was sensible enough to detect DNA alterations even after using submutagenic doses of a putative genotoxic compound.

Therefore, aim of present study was to evaluate natural plant products eventual genotoxicity by determining the frequency of mitotic crossing-over alterations in diploid strains of $A$. nidulans. The following three metabolite classes were studied: the sesquiterpene lactone (cynaropicrin), the saponin (stigmast-7en-3 $\beta$-ol-glucopyranoside) and the steroid (stigmasterol).

\section{MATERIALS AND METHODS}

\section{Haploid and diploid Aspergillus nidulans Strains}

Aspergillus nidulans haploid strains were obtained from Utrecht (Holland) stocks (UT448 and UT184) and have been described by Zucchi [15]. The strain ( $D p$ II-I) was derived from UT448 after $N$-methyl- $N$ '-nitro- $N$-nitrosoguanidine (MNNG) treatment [16-18]. Partial maps of haploid strains are shown in Clutterbuck [19] and Pires and Zucchi [20]. The mutant loci are as described: UT448- wA2 (II), white conidia; riboA1, pabaA124, biA1 (I), with requirements for riboflavine, $p$-aminobenzoic acid and biotine, respectively; AcrA1 (II), resistant to acriflavine. UT184- chaA1 (VIII), "chartreuse" conidia; pyroA4 (IV); sB3 (VI); nicB8 (VII); riboB2 (VIII), with requirements for pyridoxine, sodium thiosulphate, nicotinamyde and riboflavin, respectively; galA1 (III); facA303 (V); lacA1 (VI), unable to utilize galactose, acetate and lactose as the sole carbon source, respectively; sulA1 (I); AcrA1 (II), resistant to sulphanylamide and acriflavine, respectively. $D p$ II-I- $w$ A2 (II), white conidia; riboA1, pabaA124, bioA1 (I), with requirements for riboflavin, p-aminobenzoic acid and biotin, respectively; AcrA1 (II), resistant to acriflavine; $u v s$ (II), sensitive to UV-light [21]; $D p$ II-I, duplication of a segment from chromosome II transposed to chromosome I, inserted into paba-y genetic interval [15-18].

The UT448//UT184 and Dp II-I//UT184 diploid strains were prepared following Roper's methodology [12]. The mutant alleles were allocated to their linkage groups by mitotic haploidization [22] facilitated by treatment with $p$ fluorophenylalanine ( $p \mathrm{FA})[23,24]$.

\section{Media and Culture Conditions}

Complete medium (CM) and minimal medium (MM) were as described by Van de Vate and Jansen [25]. CM was used to maintain stock cultures. Selective medium (SM) was MM supplemented according to the requirements of each strain. Solid medium contained $1.2 \%$ agar. The strains were incubated at $37^{\circ} \mathrm{C}$ and kept at $4{ }^{\circ} \mathrm{C}$.

\section{Plant Material}

Cynaropicrin (sesquiterpene lactone-guaianolide) [26] was isolated from Moquinia kingii (H. Robinson) Gamerro

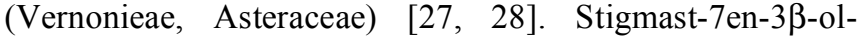
glucopyranoside (saponin) and stigmasterol (steroid) [29] were isolated from Alternanthera maritima (Gomphreneae, Amaranthaceae) [30-31]. The compounds were isolated and purified by chromatographic methods and the structures were characterized using spectroscopic methods (nuclear magnetic resonance, ${ }^{1} \mathrm{H}$ and ${ }^{13} \mathrm{C}$ NMR and electrospray mass spectrum, ESI-MS). In previous study this compounds showed in vitro antimicrobial and trypanocidal activity against human pathogenic microorganisms [27, 30]. The isolated compounds were dissolved in propylene glycol (Merck) and diluted in MM for analysis in genotoxic assay.

\section{The Homozygotization Index (HI) Short-Term Test [13]}

Mitotic crossing-over promotes homozygotization of genes present in heterozygous condition in diploids and, if the treatment induces mitotic crossing-over in the heterozygous diploids, +//+, +//-, -//+ and -//-, diploids are formed irrespective of each marker. Since the treatment is applied in MM, only heterozygous (+//- and -//+) or homozygous (+//+) diploids can develop. After haploidization when no mitotic crossing-over occurs, the ratio of haploid segregants is $4(+)$ : 4(-). As described above, selection against recessive homozygous classes after recombination between any marker and centromere reveals that HI, (i.e. the ratio between percentages of + and - segregants colonies) is changed to 2.0 , instead of expected 1.0, corresponding to $4(+): 2(-)$ and $4(+)$ : 4(-) haploid segregant colonies, respectively. Therefore an HI value higher than 2.0 indicates the occurrence of more than one mitotic crossing-over event for the given marker. Conversely, an HI value lower than 2.0 indicates, either the absence of crossing-over for the marker, or that it was not selected on MM, e.g., markers for conidia color.

Following a method recently devised for A. nidulans genetic analyses, or Delphi 4 (PLACAS, Copyright 2000 cbonato), results from genetic mitotic analyses were presented into Latin Square Tables Format (not shown). HI results estimated from those data presented in Latin Square Tables and were analysed by cluster analysis, principal component, and a modification of the $\chi^{2}$ test known as a contingency table with $1 \%$ significance.

\section{Assays Carried Out with Conidia Obtained from Each Diploid Aspergillus nidulans Strain (UT448//UT184 and Dp II-I //UT184)}

Since preliminary trials have shown that $50 \mu \mathrm{g} / \mathrm{mL}$ drug concentration inhibited $A$. nidulans development (data not shown), $25 \mu \mathrm{g} / \mathrm{mL}$ concentration was used for the three compounds in the subsequent experiments. This concentration was established as a parameter to compare the genotoxic potential of the tested drugs, and to evaluate the methods response to different chemical skeletons. Propylene glycol (2.5 $\mu \mathrm{L}$ propylene glycol/mL MM, final concentration $0.025 \%$ ) was used as solvent and negative control. Stock solutions of each test drug were prepared in propylene glycol and aliquots $(2.5 \mu \mathrm{L} / \mathrm{mL} \mathrm{MM})$ were mixed with $\mathrm{MM}$ at $50^{\circ} \mathrm{C}$ and poured into Petri dishes (final concentration of the test drugs, $25 \mu \mathrm{g} / \mathrm{mL}$ ). After incubation, conidia of the diploid strains UT448//UT184 and Dp II-I//UT184 were inoculated at four equidistant inoculation points and the plates were incubated at $37^{\circ} \mathrm{C}$ for 7 days. Various still diploid sectors that supposedly suffered mitotic crossing-over were observed. For each tested drug, and from each strain, six sectors of which morphology differed from the original diploid strain (green) were obtained.

Subsequently, the mitotic analysis was carried out. For haploidization induction, each of the six isolated sectors was 
inoculated onto $10 \mathrm{CM}+p \mathrm{FA}$ plates (at 4 equidistant points). After 5 days of incubation at $37^{\circ} \mathrm{C}$, formation of likely haploid sectors was observed: either conidia showing same color as the parental ("chartreuse" and white) or, recombinant strain (green). Each $D p$ II-I//UT184 colony originated approximately 8 haploid sectors per plate, whereas the UT448//UT184 colonies originated a mean of 6 haploid sectors per plate. Conidia from the edge of each diploid sector, is isolated in order to be phenotypically analyzed. Purified sectors were individually inoculated at 25 defined positions ( 5 x 5 patterns) on a CM plate (master plate) and incubated at $37^{\circ} \mathrm{C}$ for $48 \mathrm{~h}$. Colonies from Master Plates were replicated to SM plates using a multi-wired replicator. Colonies development was recorded after 24,48 and $72 \mathrm{~h}$ at $37^{\circ} \mathrm{C}$.

\section{RESULTS}

\section{Mitotic Analyses of Untreated UT448/UT184 and Dp II- I//UT184 Strains}

This kind of analyses allowed observing the segregation of the genetic markers in all the eight fungal chromosomes altogether. During mitotic divisions a typical Mendelian segregation (1+: 1-) is usually reported for the involved genetic markers. Genetic disturbances on this typical behavior can be attributed to the effects of the chemicals used under low doses, and allied selection against homozygous recombinant diploids for the recessive alleles, in MM. So, distortions in the allelic segregation rates indicate efficiency of the genotoxic tested drug as inducing DNA recombinogenic lesions, and subsequent HI increase. Mitotic analyses of untreated strains are reported in Table $\mathbf{1}$.

Diploid sectors analyses were performed independently. Table 1A encompasses analyzed data of all UT448//UT184 altogether. The used propylene glycol as diluent at 2.5 $\mu \mathrm{L} / \mathrm{mL} \mathrm{MM}$, final concentration of $0.025 \%$, did not alter the frequencies of mitotic crossing-over either in UT448//UT184, or $D p$ II-I//UT184 (Table 1). In the negative control experiment (diluent solution alone) diploids present a subtle allelic segregation rates distortion (different from 1:1), indicating that the allelic segregation rate results from DNA damage originating from the proper self-replication process. Since this diploid presents normal DNA repair mechanisms, such minor alterations were hardly noticed. In similar proportions, the segregation rate alterations affect the pattern of all focused gene markers scattered all over the eight fungal chromosomes [13]. In the untreated diploid strain $D p$ III/UT184 it can be seen that significant allelic segregation rate distortions arise due to low frequency of auxotrophic haploid alleles (Table 1B) in MM. Even in the absence of any recombinogenic specific inducer such results evidence that this diploid presents constitutive recombination potentials.

Table 1. Mean Homozygotization Index (HI) Obtained for the Several Genetic Markers of the Diploid Aspergillus nidulans Strains UT448//UT184 (A) and $D p$ II-I//UT184 (B) Exposed to Lactone, Saponin and Steroid at a Concentration of $25 \mu \mathrm{g} / \mathrm{mL}$ and Negative Experimental and Literature Controls

(A)

\begin{tabular}{|c|c|c|c|c|c|c|c|c|c|c|c|c|}
\hline Linkage Group & $\mathbf{I}$ & I & II & IV & VI & VII & $\mathbf{v}$ & III & $\mathbf{I}$ & VIII & \multicolumn{2}{|c|}{ Numbers of Tested Colonie } \\
\hline Literature negative control* ( 0 s UV) & 2.5 & 2.7 & 0.8 & 3.0 & 1.5 & 1.2 & 2.5 & - & - & - & 7 & 262 \\
\hline Experimental negative control & $2.0 \mathrm{a}$ & $1.7 \mathrm{a}$ & $1.0 \mathrm{a}$ & $0.8 \mathrm{a}$ & $0.8 \mathrm{a}$ & $0.3 \mathrm{a}$ & $0.3 \mathrm{a}$ & $1.7 \mathrm{a}$ & $1.5 \mathrm{a}$ & $2.0 \mathrm{a}$ & 6 & 175 \\
\hline Saponin & $86.5 \mathrm{~b}$ & $18.4 \mathrm{~b}$ & $0.43 \mathrm{~b}$ & $42.8 \mathrm{~b}$ & $24.0 \mathrm{~b}$ & $34.0 \mathrm{~b}$ & $1.9 \mathrm{~b}$ & $0.5 \mathrm{~b}$ & $2.3 \mathrm{a}$ & $2.1 \mathrm{a}$ & 6 & 175 \\
\hline Steroid & $1.8 \mathrm{a}$ & $0.5 \mathrm{a}$ & $0.8 \mathrm{a}$ & $1.9 \mathrm{a}$ & $2.1 \mathrm{a}$ & $2.3 \mathrm{~b}$ & $1.3 \mathrm{~b}$ & $0.3 b$ & $1.1 \mathrm{a}$ & $1.1 \mathrm{a}$ & 6 & 150 \\
\hline
\end{tabular}

(B)

\begin{tabular}{|c|c|c|c|c|c|c|c|c|c|c|c|c|}
\hline Genetic markers & paba & $b i$ & $w$ & pyro & lac & nic & $f a c$ & gal & ribo & cha & Diploid & Haploid \\
\hline Literature negative control* (0 s UV) & 21.8 & 21.7 & 1.2 & 21.7 & 11.7 & 18.2 & 18.2 & - & - & - & 9 & 184 \\
\hline Experimental negative control & $18.4 \mathrm{a}$ & $1.9 \mathrm{a}$ & $2.1 \mathrm{a}$ & $10.7 \mathrm{a}$ & $18.4 \mathrm{a}$ & $14.9 \mathrm{a}$ & $3.7 \mathrm{a}$ & $1.6 \mathrm{a}$ & $2.8 \mathrm{a}$ & $1.7 \mathrm{a}$ & 6 & 175 \\
\hline Saponin & $149 b$ & $7.3 b$ & $0.5 \mathrm{~b}$ & $149.0 \mathrm{~b}$ & $36.5 \mathrm{~b}$ & $150 \mathrm{a}$ & $3.8 \mathrm{a}$ & $2.5 \mathrm{a}$ & $2.8 \mathrm{a}$ & $0.7 \mathrm{~b}$ & 6 & 150 \\
\hline Steroid & $13.4 \mathrm{a}$ & $1.1 \mathrm{a}$ & $2.8 \mathrm{a}$ & $9.0 \mathrm{a}$ & $4.6 \mathrm{a}$ & $3.4 \mathrm{~b}$ & $2.4 \mathrm{a}$ & $0.9 \mathrm{a}$ & $2.6 \mathrm{a}$ & $0.7 b$ & 6 & 150 \\
\hline
\end{tabular}

- not done.

*PIRES and ZUCCHI, 1994.

Note: same letter, $X^{2}$ non-significant differences. Contingency table corrected after Yates at $1 \%(p<0.01)$. 


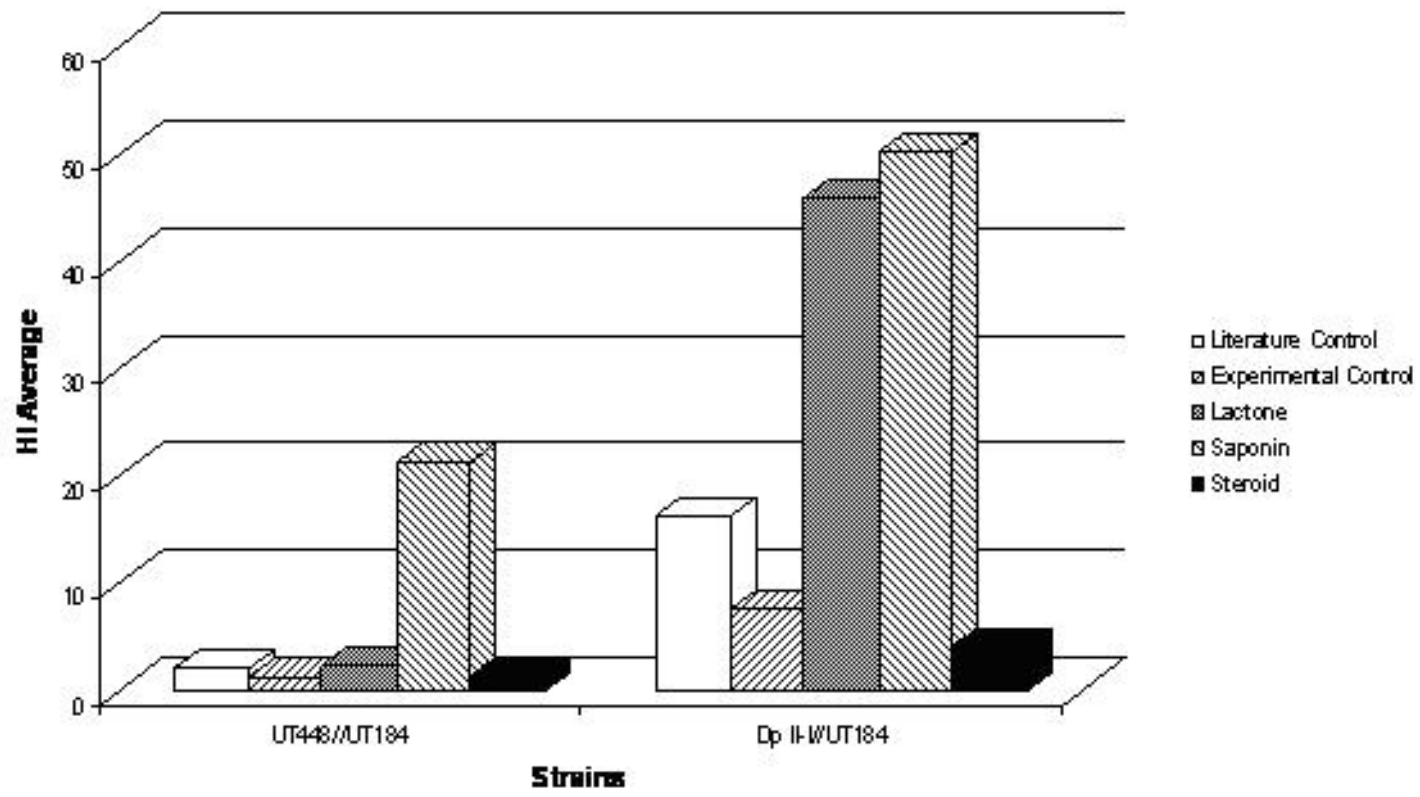

Fig. (1). Homozygotization Index (HI) average in UT448//UT184 e Dp II-I//UT184 diploids. Note: HI average values correspond to those presented in Tables $\mathbf{1 A}$ and $\mathbf{1 B}$.

\section{Natural Products Genotoxic Effects}

The genotoxic effects of natural products (lactone, saponin and steroid) have been evaluated (Table 1 and Figs. (1) and (2) in both used diploid strains (UT448//UT184 and $D p$ II-I//UT184). Conidial induction of mitotic recombination showed mean HI differences in the haploid UT448//UT184 cells exposed to the different test drugs at a concentration of $25 \mu \mathrm{g} / \mathrm{mL}$. Such cells showed a variable, undefined response pattern (Table 1A).

In the case of lactone, eight markers (exceptions paba and cha markers) among of ten showed $\mathrm{HI} \leq 2$, while $\mathrm{HI} \leq 2$ was observed for all markers in the case of the steroid. For the saponin, HI observed for the markers paba, bi, pyro, lac

and nic was higher than that observed for the control (HI > 2 ), suggesting that for these markers more than one recombinational event occurs.

For the $D p$ II-I//UT184, saponin and lactone increased the mean HI of five among ten analyzed genetic as markers compared to controls (except for $b i$ in the case of lactone of which obtained value was lower than the control), indicating a possible recombinational event (Table 1B). Fig. (1) shows average HI values for all studied nutritional markers. In-

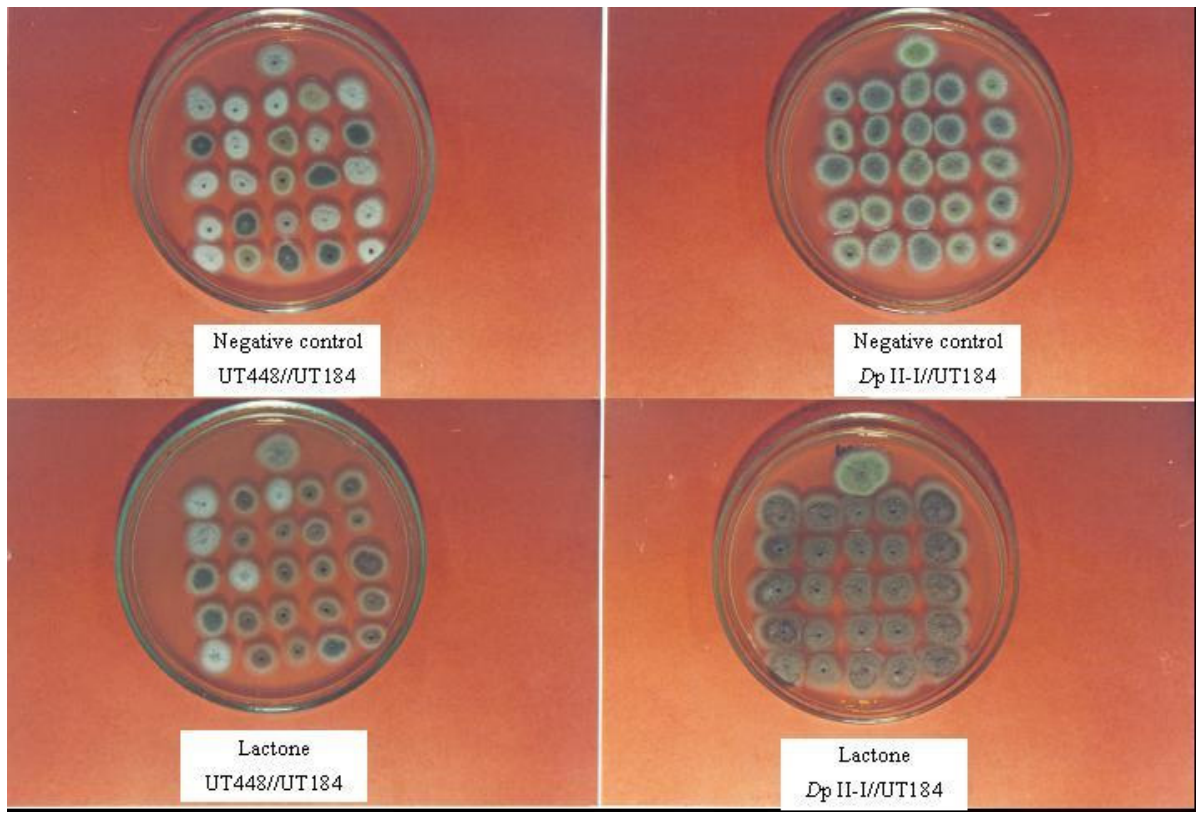

Fig. (2). Master plate containing 25 colonies of segregants growing on CM for experimental negative control and treated with lactone $(25 \mu \mathrm{g} / \mathrm{mL})$ for two strains of $A$. nidulans (UT448//UT184 e Dp II-I//UT184) used. 
creased distortions occurring after several treatments are easily seen.

For the steroid, all markers showed HI values similar to or lower than those obtained for the control, indicating the absence of recombinational events. In both strains HI values obtained for the $w, f a c$, gal, ribo and cha markers of both strains were equal to or lower than the control value, with the $w$ marker (color marker) being not selectable on MM. The two studied strains are known to differ in their genetic characteristics [13]. The UT448//UT184 strain is control normal for all known repair mechanisms, while the $D p$ II-I//UT184 strain is deficient in photoreactivation and excision repair, with recombination being the main form of DNA damage repair. Since HI exactly expresses recombinational events occurring during mitosis, one can assume that drugs inducing HI higher than the control possess genotoxic and recombinogenic potential.

\section{Statistical Analysis}

Statistical analysis [4, 32], cluster analysis and principal component (Fig. 3) were performed to determine similarity degree in terms of genotoxic potential for the tested drugs and for the experimental control and their distribution between the two strains. The isolated compounds were used as variables, and genetic marker (paba, bi, w, pyro, lac, nic, and ac) as characters.

For the UT448//UT184 strain, the experimental control, lactone and steroid formed one group and saponin another group up to $65 \%$ of the mean Euclidean distance (ED). Based on the principal component analysis, traits responsible for this distribution were: $\mathrm{X}$ axis, the genetic marker nic $(\lambda=$

(A)
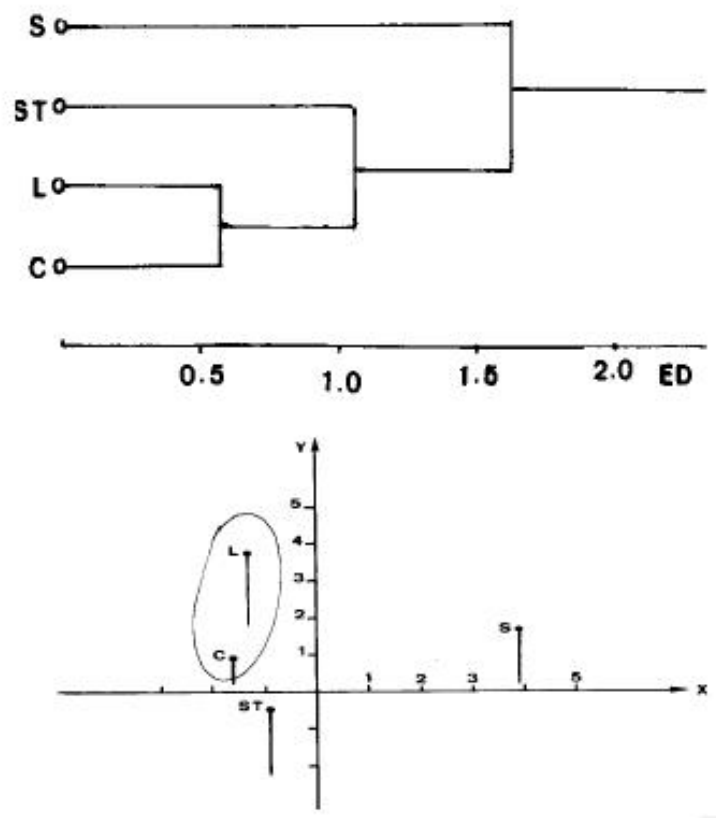

$6.89230 ; 68.92 \%) ; \mathrm{Y}$ axis, the genetic marker cha $(\lambda=$ $2.75960 ; 27.60 \%) ; Z$ axis, the genetic marker $w(\lambda=0.34810$; $3.48 \%$ ). This analysis mainly indicates that the lactone and steroid did not induce recombination events since they formed a group similar to the negative control, whereas an increased number of recombination events were observed for saponin, which therefore constituted a separate group.

For the $D p$ II-I//UT184 strain, the control and steroid formed one group up to $65 \%$ of the mean $\mathrm{ED}$, followed by the lactone $(85.78 \% \mathrm{ED})$, which formed a group with the two first substances and saponin. The traits responsible for this distribution as determined by analysis of the main components were: $X$ axis, the genetic marker paba $(\lambda=5.71232$; $57.12 \%)$; $\mathrm{Y}$ axis, the genetic marker paba $(\lambda=3.41744$; $34.17 \%) ; Z$ axis, the genetic marker cha $(\lambda=0.87024$; $8.70 \%)$. These results indicate a steroid behavior similar to the control, suggesting that the steroid did not induce any recombinational event; while lactone and saponin formed groups separate from the control and steroid, indicating a genotoxic and recombinogenic potential for the former.

\section{DISCUSSION}

Human diet usually contains about 200 to $300 \mathrm{mg} / \mathrm{day}$ of steroids [33]. Plant materials and especially vegetable oils contain free, esterified and glycosylated steroids [34]. These compounds are incorporated by the cell membrane, playing an important role in the treatment of hypercholesterolemia. According to Piironen et al. [5], diets rich in these compounds are recommended. However, it should be noted that oral saponins ingestion is submitted to metabolization, undergoing hydrolysis, resulting into free aglycon (steroid) and sugar. Besides, the steroidal saponins shown surfactant prop-

\section{(B)}
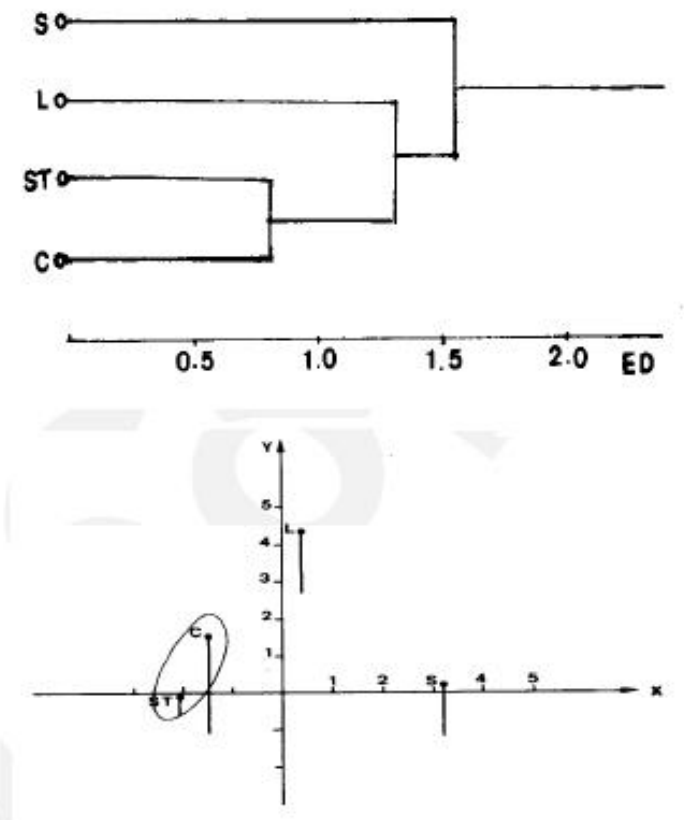

Fig. (3). Dendrogram and principal component analysis of the mean homozygotization indices (HI) obtained for the different genetic markers of the diploid Aspergillus nidulans strains (A) UT448//184 and (B) Dp II-I//UT184 induced by (L) lactone, (S) saponin and (ST) steroid $(25 \mu \mathrm{g} / \mathrm{mL})$ and $(\mathrm{C})$ negative control. 
erties and induce hemolysis by erythrocytic membrane instability [35].

Lactones are terpenoids consisting of various skeletons are frequently present in species of the family Asteraceae. Studies determining in vitro genotoxic activity of lactones on human lymphocytes showed that skeletons such as erematholide-C and 15-deoxygoyazensolide presented no genotoxic effects [36]. Similar results were obtained for pseudoguaianolide, goyazensolide [37] and eremanthine [38]. However, according to Burim et al. [39], glaucolide Bt presents no clastogenic action on in vivo mammalian cells but, on the other hand, it showed in vitro cytotoxic and clastogenic effects.

Since there are considerable dispute about natural products genotoxicity (mainly due to a lack of adequate methodologies), a short-term test which assesses specifically for genotoxic events could play a crucial role in related matters $[13,14]$. In this ways, used $A$. nidulans versatile eukaryotic in vivo system, was useful to clarify the biological action of eventual genotoxic compounds, and to help understanding the possible modulation of its action by a holistic interaction of many cellular systems. Of course, it seems likely that there are limitations towards using A. nidulans as a mammal surrogate due to differences in the molecular environment, and to the more complex genetic interactions in mammals.

Comparing obtained results for the two studied strains, the steroid did not induce recombinational alterations in both strains, while saponin led to significant HI increase as compared to the control despite presence of normal repair mechanisms in the UT448//UT184 strain. Lactone showed an interesting profile, with no recombinational activity detected in the UT448//UT184 strain, while in the $D p$ III//UT184 strain recombinogenic potential was observed in five of the analyzed markers (Table 1B).

Furthermore, because tested drugs at a concentration of $25 \mu \mathrm{g} / \mathrm{mL}$ exerted different effects on the ten analyzed genetic markers, used methodology permits detecting the genotoxic potential of plant secondary metabolites using even small samples $(10 \mathrm{mg})$. Despite such trends present shortterm test has been used to disclose suspected genotoxicity rapidly and efficiently. Besides, the test is very sensitive as genotoxicity can be detected even after application of low doses of a given agent, such as UV [13], benzene fumes [14], sodium nitroprusside [40], benznidazole [41], cisplatin and cytosine arabinoside [42] and X-ray [43]. These characters altogether allied to test inexpensiveness, suggest involved eukaryote microorganism (A. nidulans) can be proposed as a cell model to guide early approaches towards rapid screening of genotoxic potential and biological activities of many chemicals.

In conclusion, above results and comments suggest that employed short-term test used bears remarkable potentials to evaluate the genotoxic/carcinogenic effects of bioactive natural products, since needed HI can be easily calculated for any heterozygous marker of $A$. nidulans diploid strains.

\section{ACKNOWLEDGEMENTS}

This work was supported by FAPESP (Fundação de Amparo à Pesquisa do Estado de São Paulo-Brazil), CNPq (Conselho Nacional de Desenvolvimento Cientifico e Tecno-
logico-Brazil) and CAPES (Coordenação de Aperfeiçoamento de Pessoal de Nivel Superior-Brazil).

\section{REFERENCES}

[1] Bohlmann C. In: Barton D, Ollis WD, Eds. Advances in Medicinal Phytochemistry. London, John Libbeg. 1986; 37-46.

[2] Biavatti MW, Vieira MFGF, Fernandes JB, Albuquerque A, Magalhães CMI, Pagnocca FC. Chemistry and bioactivity of Raulinoa echinata Cowan, an endemic Brazilian Tutaceae species. Phytomedicine 2001; 8: 121-24.

[3] Picman AK. Biological activities of sesquiterpene lactones. Biochem Syst Ecol 1986; 14: 255-81.

[4] Alcaráz LE, Blanco SE, Puiz OE, Tomás F, Ferretti FH. Antibacterial activity of flavonoids against methicillin-resistant Staphylococcus aureus strains. J Theor Biol 2000; 205: 231-40.

[5] Piironen V, Lindsay DG, Miettinen TA, Toivo J, Lampi A. Plants sterols: biosynthesis, biological function and their importance to human nutrition. J Sci Food Agric 2000; 80: 939-66.

[6] Wiseman H. Dietary influences on membrane function: importance in protection against oxidative damage and disease. J Nutr Biochem 1996; 7: 2-15.

[7] Zucchi TMAD, Pires LTA In: Melo IS, Azevedo JL, Ed. Microbiologia Ambiental. Jaguariúna, EMBRAPA 1997; 357-413.

[8] Kunz BA, Haynes RH. Phenomenology and genetic control of mitotic recombination in yeast. Ann Rev Genet 1981; 15: 57-80.

[9] Cairns J. The origin of human cancers. Nature 1981; 289: 353-57.

[10] Schiestl RH. Non-mutagenic carcinogens induce intrachromosomal recombination in yeast. Nature $1989 ; 337: 285-8$.

[11] Fabre F, Roman H. Genetic evidence for inducibility of recombination competence in yeast. PNAS 1977; 74: 1667-71.

[12] Roper JA. Production of heterozygous diploids in filamentous fungi. Experientia 1952; 8: 14-5

[13] Pires LTA, Zucchi TMAD. A new method to detect potential genotoxic agents using mitotic crossing-over in diploid strains of $A$. nidulans. Brazil J Genet 1994; 17: 371-6.

[14] Zucchi TD, Zucchi FD, Melo IS, Poli P, Zucchi TMAD. A shortterm test adapted to detect the genotoxic effects of environmental volatile pollutants (benzene fumes) using the filamentous fungus Aspergillus nidulans. J Environ Monit 2005; 7: 598-602.

[15] Zucchi TMAD. Isolation of a putatirecombination mutant of $A$. nidulans. Brazil J Genet 1990; 13: 409-24.

[16] Zucchi TMAD. Location of the suppressor of meth A17 mutation in the 30 mutant of $A$. nidulans. Brazil J Genetics 1990; 13: 425-43.

[17] Castro-Prado MAA, Zucchi TMAD. Stabilization of a duplicated segment $D p$ (II-I) in an $u v s$ mutant of $A$. nidulans through genetic mechanisms. Brazil J Genet 1991; 14: 239-48.

[18] Castro-Prado MAA, Zucchi TMAD. Meiotic segregation of a recessive gene $(w \mathrm{~A} 2)$ in a $D p(\mathrm{II}-\mathrm{I})$ of $A$. nidulans. Brazil J Genet 1991; 14: 249-60.

[19] Clutterbuck AJ. In: O'Brien SJ, Ed. Genetic maps. New York, Cold Spring Harbor 1993; 71-84.

[20] Pires LTA, Zucchi TMAD. Ribonucleic acid treatment alters gene expression in diploid expression in diploid strains of Aspergillus nidulans. Cell Mol Biol 1998; 44: 303-13.

[21] Marin JM, Zucchi TMAD. Genetic analysis of some factors affecting mitotic and meiotic behavior of a mutant of Aspergillus nidulans. Revista Brasileira de Genética 1991; 14: 9-20.

[22] Forbes E. Use of mitotic segregation for assigning genes to linkage group in A. nidulans. Heredity 1959; 13: 67-80.

[23] Lhoas P. Mitotic haploidization by treatment of Aspergillus niger diploids with $p$-phenylalanine. Nature 1961; 190: 744

[24] Morpurgo C. Somatic segregation induced by p-fluorphenylalanine in Aspergillus. Newsletter 1961; 2: 10.

[25] Van de Vate C, Jansen GIO. Meiotic recombination in a duplication strain of $A$. nidulans. Genet Res 1978; 31:29-52.

[26] Bohlmann F, Singh P, King RM, Robinson H. New guaianolides from Pseudostifftia kingii. Phytochemistry 1982; 21: 1171-2.

[27] Schinor EC, Salvador MJ, Albuquerque S, Ito IY, Dias DA. Trypanocidal and antimicrobial activities of Moquinia kingii. Phytomedicine 2004; 11: 224-9.

[28] Robinson H. Notis on the tribus Erenothamneae, Gundelieae and Moquinia, with comparisons of their pollen. Taxon 1994; 43: 3344.

[29] Kojima H, Sato N, Hatano A, Ogura H. Sterol glucosides from Prunella vulgaris. Phytochemistry 1990; 29: 2351-5. 
[30] Salvador MJ, Zucchi OLAD, Candido RC, Ito IY, Dias DA. In vitro antimicrobial activity of crude extracts and isolated constituents of Alternanthera maritima (Amaranthaceae). Pharm Biol 2004; 42: 138-48.

[31] Siqueira JC, Guimarães EF. Amaranthaceae do Rio de Janeiro - o gênero Alternanthera Forsk. Rodriguésia 1984; 36: 21-40.

[32] Alves SB. Controle microbiano de insetos. São Paulo: Manole; 1986.

[33] Gylling H, Miettinen TA. Phytosterols, analytical and nutritional aspects, in Functional Foods. A new Challenge for the Food Chemist. Budapest: Publishing Company of TUB; 1999.

[34] Wojciechowski ZA. In: Patterson GW, Nes WD, Eds. Physiology and Biochemistry of Sterols. Champaign,. American Oil Chemists' Society 1993; 361-95.

[35] Zhang J, Zhiyun M, Zhang M, Deshun M, Suixu X, Kodama H. Effect of six steroidal saponins isolated from anemarrhenae rhizoma on platelet aggregation and hemolysis in human blood. Clinica Chimica Acta 1999; 289: 79-88.

[36] Vicentini-Dias VEP. Estudo da ação citotóxica das lactonas sesquiterpênicas eremantolido $\mathrm{C}$ e 15-deoxigoyazensolido, sobre medula óssea de ratos e linfócitos humanos. Ph.D. thesis, Faculdade de Medicina de Ribeirão Preto. Universidade de São Paulo, Ribeirão Preto, São Paulo 1992.
[37] Mantovani MS, Takahashi CS, Vichnewshi W. Evaluation of the genotoxic activity of the sesquiterpene lactone goyazensolide in mammalian systems in vitro and in vivo. Rev Bras Genet 1993; 16 : 967-75.

[38] Dias FL, Takahashi CS, Sakamoto-Hojo ET, Vichnewshi W, Sarti SJ. Genotoxicity of natural cercaricide "sucupira" oil and eremanthine in mammalian cells in vitro and in vivo. Environ Mol Mutagen 1995; 26: 338-44.

[39] Burim RB, Canalle R, Callegari-Lopes JL, Takahashi S. Genotoxic action of the sesquiterpene lactone glaucolide $\mathrm{B}$ on mammalian cells in vitro and in vivo. Gen Mol Biol 1999; 22: 401-6.

[40] Chiuchetta SJR, Castro-Prado MAA. Genotoxic evaluation of sodium nitroprusside in Aspergillus nidulans. Gen Mol Biol 2005; 28: 798-803.

[41] Kaneshima EN, Castro-Prado MAA. Benznidazole-induced genotoxicity in diploid cells of Aspergillus nidulans. Memórias do Instituto Oswaldo Cruz 2005; 100: 325-30.

[42] Miyamoto CT, Sant'anna JR, Franco CCS, Castro-Prado MAA. Genotoxicity (mitotic recombination) of the câncer chemotherapeutic agents cisplain and cytosine arabinoside in Aspergillus nidulans. Food Chem Toxicol 2007; 45: 1091-5.

[43] Stoll LB, Cremonesi FCA, Pires LTA, Zucchi TD, Zucchi TMAD. Induction of mitotic crossing-over in diploid strains of Aspergillus nidulans using low-dose X-Ray. Gen Mol Res 2008; 7: 467-75.

C) Salvador et al.; Licensee Bentham Open.

This is an open access article distributed under the terms of the Creative Commons Attribution License (http://creativecommons.org/licenses/by/2.5/), which permits unrestrictive use, distribution, and reproduction in any medium, provided the original work is properly cited. 